\title{
Research Article \\ Effects of Different Mordants on Silk Fabric Dyed with Onion Outer Skin Extracts
}

\author{
Mohammad Gias Uddin \\ Department of Textile Engineering, Faculty of Engineering, Ahsanullah University of Science and Technology, Dhaka 1208, Bangladesh \\ Correspondence should be addressed to Mohammad Gias Uddin; giasdtt@gmail.com
}

Received 6 September 2014; Accepted 12 November 2014; Published 10 December 2014

Academic Editor: Phillip W. Gibson

Copyright (C) 2014 Mohammad Gias Uddin. This is an open access article distributed under the Creative Commons Attribution License, which permits unrestricted use, distribution, and reproduction in any medium, provided the original work is properly cited.

\begin{abstract}
At present, a higher demand is put towards the use of natural dyes due to increased awareness of the environmental and health hazards associated with the synthesis and use of synthetic dyes. This research was conducted using onion outer skins as a potential source of natural plant dyes. In this study, extraction of dye was carried out in aqueous boiling method. Premordanting technique was followed using different mordants, namely alum, ferrous sulphate, tin, tannic acid, tartaric acid, and their combinations on silk fabric. Fabric samples dyed without using any mordant were then compared with the dyed samples pretreated with the mordants. The range of colors developed on dyed materials was evaluated by measuring the color values with respect to $K / S$ values and color coordinates. It was concluded that the color values were found to be influenced by the addition of mordants, and thus different fashion hues were obtained from the same amount of dye extract using different mordants. Ferrous sulphate was found as the most influential mordant. $\Delta E_{\mathrm{cmc}}$ values between unmordanted (Reference dyed) and metallic mordanted fabric samples were found higher than those between unmordanted and nonmetallic mordanted fabric samples. The dyed samples were evaluated for color fastness to washing, light, drycleaning, rubbing, and perspiration. The color fastness properties were found to be satisfactory and improved in many cases. From the fastness results, it was obvious that these dyes can also be applied on silk fabric without using any mordant if required.
\end{abstract}

\section{Introduction}

Natural dyes are noncarcinogenic, produce soothing and exclusive color to the textiles, and have better biodegradability and higher compatibility with the environment [16]. Among the natural dyes, plant dyes are potential sources because of their easy availability and abundant nature. Onion outer skins are the most commonly discarded household and commercial food waste which can be used as dyes for coloring natural textile materials. These dyes, which are known as pelargonidin (3,5,7,4-tetrahydroxyanthocyanidin) [7] (see Figure 1), work like acid dyes that can dye the protein fibers at high efficiency [8]. The amount of pelargonidin was found to be $2.25 \%$ in certain solvent extraction process using soxhlet apparatus [7]. Due to presence of four hydroxy groups (Auxochrome groups) pelargonidin exhibits good dyeing properties for dyeing of natural fibers $[7,9]$.

However, with the increased interest in natural plant dyes a greater importance was given to using mordant. Most of the natural dyes require some sort of mordant to set permanently in any fiber. Metal ions of mordants act as electron acceptors for electron donors to form coordination bonds with the dye molecules, making them insoluble in water [10]. This leads to improve dye uptake and retention, which result in a greater depth of shade and color fastness properties [11]. Common mordants are alum, chrome, stannous chloride, copper sulphate, ferrous sulphate, and so forth [12]. Chrome and copper are considered to be harmful for human skin as objectionable heavy metals beyond a certain limit of their presence [13]. Organic substances that have been used as mordants are mud, blood, and cow dung [14]. Also to reduce the effect of some toxic mordants, natural mordants such as tannins are recommended, as they can provide fabrics with characteristics similar to those provided by synthetic mordants [15].

Again, depending on the metal character of mordant, the complex formation not only strengthens dyestuff fixation on the substrate but also changes the color of dyeing. In 


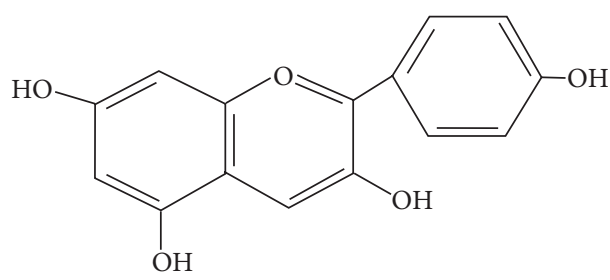

FIGURE 1: Chemical structure of pelargonidin.

some cases the resulting change in shade can be seen as an opportunity to steer color in a wider range. Different types of mordants and their combination on the same natural dye may darken, brighten, or drastically alter the color of the dyemordant solution and influence the shade of the final product [16] which may be a desired effect as well as an unwanted phenomenon [17]. So, final color, its brilliance, and color fastness properties are not only dependent on the dye itself but are also determined by varying concentration and suitable application of mordants.

\section{Materials and Methods}

2.1. Materials. The raw silk fabric ( 22 denier warp, 22 denier weft, 132 ends/inch, 132 picks/inch, and $22 \mathrm{~g} / \mathrm{m}^{2}$ fabric area density) purchased from Sopura Silk Ltd., Dhaka, Bangladesh, was used in this study.

\subsection{Methods}

2.2.1. Extraction Process. The onion skins were dried under direct sunlight and grinded into small units with the help of grinding machine. The wastages are removed using a fine strainer and finally weight was taken. After drying, crushing, and straining, the weight of $1 \mathrm{~kg}$ skins was found to be $805 \mathrm{gm}$. The dried and crushed skins were shown in Figure 2.

The color component was extracted from the skins in aqueous extraction process. It was done by extracting fixed quantity of crushed skins under $\mathrm{pH} 5$ with a material to liquor ratio of 1:10 (weight of crushed skins in g; amount of water in $\mathrm{mL}$ ) at boil for $60 \mathrm{~min}$. In each process of extraction, the mixture was cooled down and finally the dye extracts were filtered accurately.

2.2.2. Degumming. The raw silk fabric was degummed in an aqueous soap solution ( $15 \mathrm{~g} / \mathrm{L}$ soap) at $\mathrm{pH}$ 9. The material to liquor ratio during the treatment was maintained at 1:50. The temperature was gradually raised to $80^{\circ} \mathrm{C}$ and run for 60 minutes. The degummed fabric was washed with $2 \mathrm{~g} / \mathrm{L}$ detergent at $65^{\circ} \mathrm{C}$ for $10 \mathrm{~min}$.

2.2.3. Bleaching. Then, the fabric was treated with $35 \%$ hydrogen peroxide $(3 \mathrm{~mL} / \mathrm{L})$ solution, maintaining a material to liquor ratio of $1: 50$ at $\mathrm{pH} 9$ and temperature $60^{\circ} \mathrm{C}$ for 60 minutes followed by wash with $2 \mathrm{~g} / \mathrm{L}$ detergent at $65^{\circ} \mathrm{C}$ for $10 \mathrm{~min}$.
2.2.4. Mordanting. Premordanting was carried out on silk fabric using 5\% (on fabric weight) of ferrous sulphate, alum, stannous chloride, tannic acid, and tartaric acid mordants individually and using four different combinations of mordants such as ferrous sulphate-alum $(2.5 \%+2.5 \%)$, ferrous sulphate-alum-tin $(2 \%+2 \%+1 \%)$, alum-tin $(2.5 \%+2.5 \%)$, and alum-tin-tannic acid $(2 \%+2 \%+1 \%)$ at $60^{\circ} \mathrm{C}$ for 60 minutes keeping material to liquor ratio 1:30. Again, cream of tartar (CT) was used as a mordant assistant with alum and stannous chloride separately.

2.2.5. Dyeing. Dyeing was carried out in exhaust method with the dye extracts as per standard dyeing conditions recommended for silk fabric [18] at $80^{\circ} \mathrm{C}$ for 60 minutes under $\mathrm{pH}$ 5, keeping material to liquor ratio 1:50 in a IR sample dyeing machine. Opticid PSD $(1.5 \mathrm{~g} / \mathrm{L})$ was used as a buffering agent in the extracted dye liquor.

2.2.6. Color Yield of Dyed Fabrics. Dyed textile samples were analyzed by measuring the reflectance curve between 350 and $750 \mathrm{~nm}$ by the reflectance spectrophotometer with illuminant $D_{65}$ at $10^{\circ}$ observer. The minimum of the curve $\left(R_{\min }\right)$ was used to determine the ratio of light absorption $(K)$ and scatter (S) via the Kubelka-Munk function using [19]

$$
\left(\frac{K}{S}\right)_{\text {Dyed }}=\frac{\left(1-R_{\min }\right)^{2}}{2 R_{\min }} .
$$

2.2.7. Color Coordinates of Dyed Fabrics. The color coordinates of the dyed samples were determined by a dual beam reflectance spectrophotometer using color-matching software (Datacolor International, USA) and the three parameters $L^{*}, a^{*}$, and $b^{*}$ were determined in the CIELab system. In addition, chroma $\left(C^{*}\right)$ and hue $(h)$ values were determined from the spectrophotometer readings.

2.2.8. Color Difference $\left(\Delta E_{c m c}\right)$. Mordanted and unmordanted dyed samples were measured in the mentioned spectrophotometer and $\Delta E_{\mathrm{cmc}}$ value was determined to show the color difference between them taking unmordanted dyed sample as standard.

2.2.9. Color Fastness. Washing fastness test was carried out in ISO 105 C02 method, light fastness in ISO 105 B02 method, dry cleaning fastness in ISO 105 D01 method, rubbing fastness in ISO 105 X12 method, and perspiration fastness in ISO 105 E04 method.

\section{Results and Discussion}

3.1. Dyed Samples. The use of mordants produced different shades on silk dyed with onion extracts which were shown in Table 1 .

3.2. Color Measurements of Dyed Fabrics. The results of color measurements of the dyed silks were shown in Table 2. 


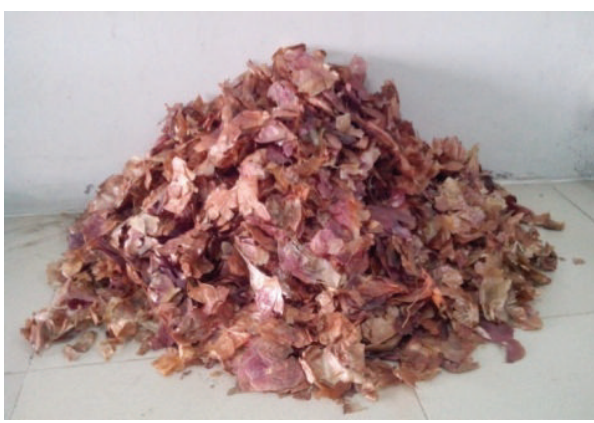

(a) Dried onion skins

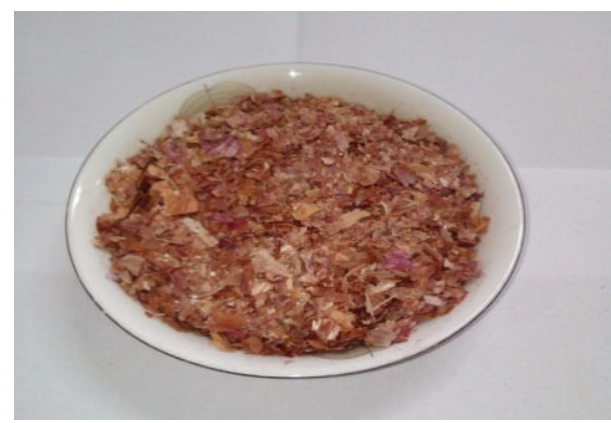

(b) Crushed onion skins

Figure 2: Dried and crushed onion skins.

TABLE 1: Shades of dyed silk.

\begin{tabular}{|c|c|}
\hline Mordant & $\begin{array}{c}\text { No mordant (Reference } \\
\text { dyed) }\end{array}$ \\
\hline Shade & \\
\hline
\end{tabular}

(1) Camel
Ferrous sulphate

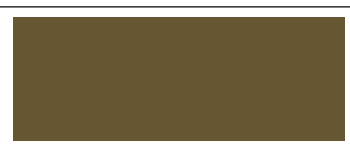

(2) Otter
Ferrous sulphate-alum

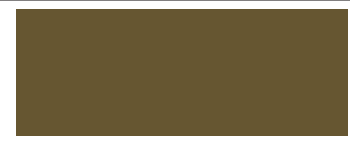

(3) Dusky dull green
Ferrous sulphate-alum-tin

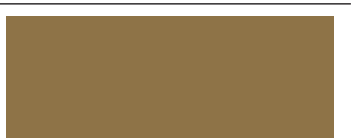

(4) Bone brown

\begin{tabular}{lc}
\hline Mordant & Alum \\
\hline Shade & \\
& (5) Amber gold \\
\hline Mordant & Tin + CT \\
Shade &
\end{tabular}

(9) Clay

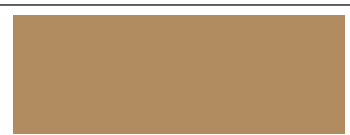

(6) Oak buff Alum + Tin Tin

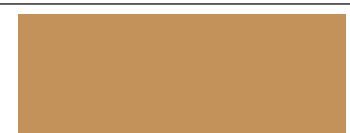

(7) Honey yellow

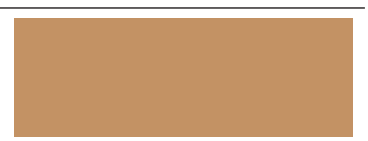

(8) Sandstorm

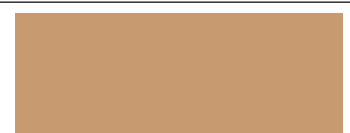

(10) Toast

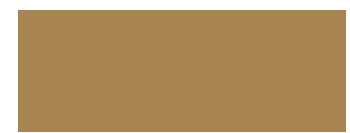

(11) Honey gold
Tartaric acid

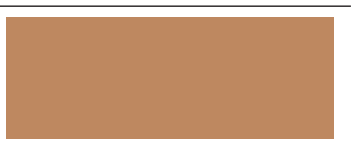

(12) Toasted nut
3.2.1. Color Yield of Dyed Fabrics. K/S value of the unmordanted dyed sample was found to be 11.235. In the mordanting method, mordant resulted in improved color yield of the dyed fabrics, except tin-CT and alum-CT. Ferrous sulphate as a mordant significantly increased the color yield of silk. The $K / S$ value was found to be 15.284 using ferrous sulphate which showed the relative surface color strength value of $136.04 \%$ considering the unmordanted dyed sample as standard. Besides, using ferrous sulphate-alum as a combination, the maximum color strength $146.94 \%$ $(K / S=16.509)$ and using ferrous sulphate-alum-tin as a combination the color strength $131.93 \%(K / S=14.822)$ was found.

Among ferrous sulphate, alum, tin, tannic acid, and tartaric acid mordants, when these were used individually in a single mordanting process on silk, the order of color yield was found to be ferrous sulphate $>$ tartaric acid $>$ tin $>$ tannic acid $>$ alum, that is, color yield gradually decreased when approached from ferrous sulphate to alum. Again, among the four different combinations of mordants, that is, ferrous sulphate-alum, ferrous sulphate-alum-tin, alumtin, and alum-tin-tannic acid, the order in the combination process was found to be ferrous sulphate-alum $>$ ferrous sulphate-alum-tin $>$ alum-tin $>$ alum-tin-tannic acid.

The increase in $K / S$ values due to mordanting reveals that dye molecules are capable of forming metal complex with the positively charged metals. In case of silk fibers, dye anions and metal cations have strong attraction towards positively charged amino and negatively charged carboxyl groups, respectively. Hence, they enter the fiber and form ionic bonding between dye and fiber and metal and fiber and finally with dye and metal ions. The dye-metal chellates thus produced also form coordinate bonds with the uncharged amine $\left(-\mathrm{NH}_{2}\right)$ groups of silk. Again, one molecule of dye can form a bond with one site of fiber molecule. But one molecule of mordant can form bonds with two or more molecules of dyes. As a result, when the mordant molecule binds on to fiber it holds two molecules of dye with it. Therefore, using mordant, the color yield was increased.

It is known that some transition metal ions can bond strongly with natural dye molecules due to their ability to form coordination complexes and thus produce deep color on the fabric. Iron salts such as ferrous sulphate as transition metal mordant form a large number of complexes with 
TABLE 2: Color yield, color coordinates, and color difference of the dyed fabrics.

\begin{tabular}{|c|c|c|c|c|c|c|c|c|}
\hline \multirow{2}{*}{ Mordant type } & \multirow{2}{*}{$K / S$ at $\lambda_{\max }$} & \multirow{2}{*}{ Color strength $\%$} & \multicolumn{5}{|c|}{ Color coordinates } & \multirow{2}{*}{$\Delta E_{\mathrm{CMC}}$} \\
\hline & & & $L^{*}$ & $a^{*}$ & $b^{*}$ & $C^{*}$ & $h^{0}$ & \\
\hline No mordant (Reference dyed) & 11.235 & 100 & 63.19 & 15.53 & 25.43 & 29.69 & 58.92 & - \\
\hline $\mathrm{Fe}$ & 15.284 & 136.04 & 37.54 & 4.23 & 18.61 & 19.09 & 77.19 & 15.25 \\
\hline $\mathrm{Fe}+$ Alum & 16.509 & 146.94 & 39.16 & 4.56 & 21.11 & 21.59 & 77.82 & 15.08 \\
\hline $\mathrm{Fe}+$ Alum + Tin & 14.822 & 131.93 & 50.76 & 8.45 & 25.41 & 26.78 & 71.60 & 9.60 \\
\hline Alum & 12.980 & 115.53 & 55.81 & 9.72 & 34.92 & 36.25 & 74.45 & 12.25 \\
\hline Alum + CT & 9.3829 & 83.51 & 60.58 & 10.88 & 26.62 & 28.76 & 67.77 & 5.92 \\
\hline Alum + Tin & 13.411 & 119.37 & 63.12 & 15.22 & 33.79 & 37.06 & 65.76 & 6.29 \\
\hline Tin & 14.188 & 126.28 & 63.24 & 15.62 & 29.38 & 33.27 & 62.00 & 2.82 \\
\hline $\operatorname{Tin}+\mathrm{CT}$ & 9.0721 & 80.75 & 65.94 & 13.67 & 26.73 & 30.02 & 62.92 & 2.92 \\
\hline Tannic acid (TA) & 13.795 & 122.79 & 65.93 & 14.22 & 27.04 & 30.56 & 62.26 & 2.56 \\
\hline Alum + Tin + TA & 11.719 & 104.31 & 57.88 & 11.85 & 31.28 & 33.45 & 69.26 & 7.86 \\
\hline Tartaric Acid & 14.484 & 128.93 & 60.60 & 18.45 & 28.23 & 33.72 & 56.84 & 2.71 \\
\hline
\end{tabular}
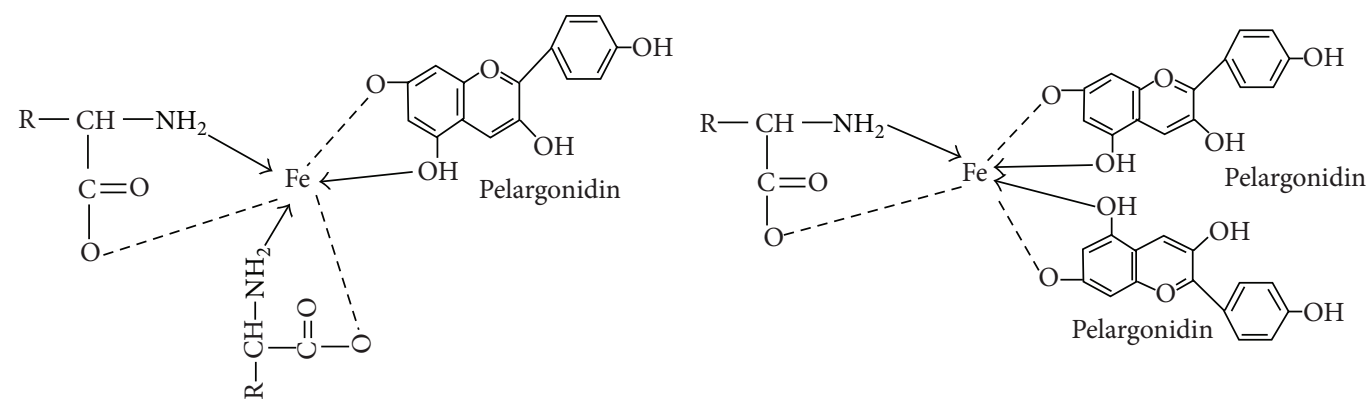

Figure 3: Possible structures of pelargonidin with $\mathrm{FeSO}_{4}$ on silk.

the dye molecules, mostly octahedral ones with coordination number 6. As a result, some coordination sites remain unoccupied when they interact with the fiber and at that time functional groups such as amino and carboxylic groups on the silk fiber can occupy these unoccupied sites. Thus, ferrous sulphate salts can form a ternary complex on one site with the fiber and in the other site with the dye. This resulted in higher dye uptake as well as shade change due to mordanting with ferrous sulphate. On the other hand, aluminium and tin salts formed weak coordination complexes with the dye. This tends to form quite strong bonds with the dye molecule but not with the fiber. Thus, they block the dye and reduce its interaction with the fiber. This is the reason behind the lower $K / S$ values in case of aluminium and tin than those obtained from ferrous sulphate salts [13, 20-23].

The possible structures of complexes with pelargonidin dye molecules and ferrous sulphate or alum in premordanting of silk were shown in Figures 3 and 4, respectively [9].

In contrast, as a mordant assistant cream of tartar (CT) decreased the color yield of dyed fabrics when used with alum or tin.

3.2.2. Effect of Mordanting on Color Characteristics of Dyed Silk. The $\Delta L^{*}$ values of the dyed silk samples as shown in Figure 5 indicated that ferrous sulphate mordant resulted in the highest increase in color $\operatorname{depth}\left(\Delta L^{*}\right.$ values were lower), followed by alum when single mordant was considered. Darkness was increased $40.59 \%$ using ferrous sulphate mordant in comparison to the reference dyed sample. This could be attributed to the affinity of mordant with color and fabric.

Among the combined applications of mordants, in all cases, it was observed that the highest darkness achieved by ferrous sulphate was reduced while alum was used with ferrous sulphate and further reduced while tin was used with the combination of ferrous sulphate and alum. In contrast, tin-CT and tannic acid produced lighter shades but when tannic acid was used with alum and tin in combination, the color depth was found to be increased. Besides, cream of $\operatorname{tartar}$ (CT) with alum or tin brought changes in the lightness scale of the dyed fabrics. The test results showed that CT increased $L^{*}$ value when used along with alum or tin than their individual use.

From the $\Delta a^{*}$ values of dyed samples as shown in Figure 6, it was clear that the addition of ferrous sulphate mordant increased the greenness quality $72.76 \%$ of the reference samples. On the contrary, tartaric acid improved $18.80 \%$ in redness value from the corresponding reference sample.

The $\Delta b^{*}$ values of the samples as shown in Figure 7 indicated that ferrous sulphate and ferrous-alum mordanted samples were bluer than the reference sample. In other cases, yellowness of dyed fabrics was increased. Significant 

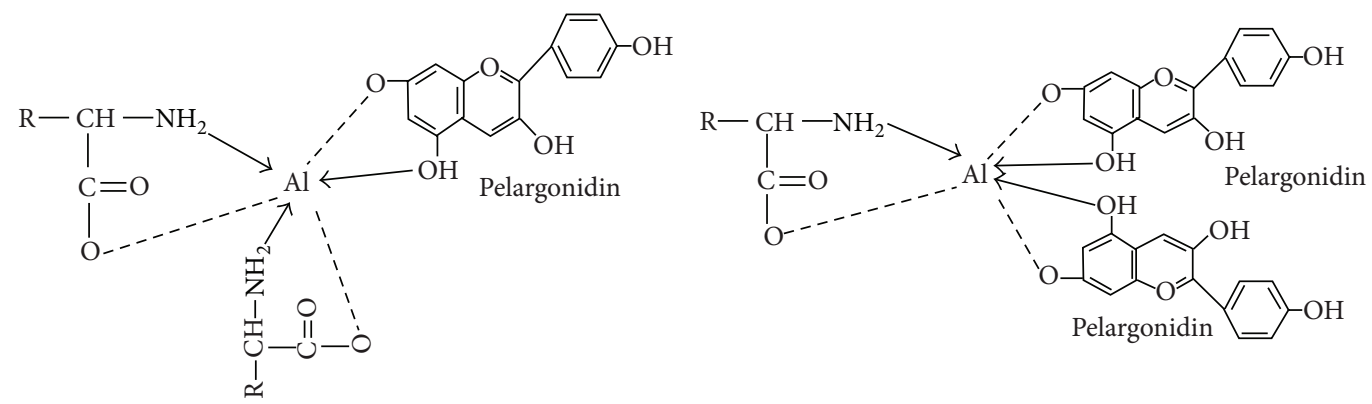

Figure 4: Possible structures of pelargonidin with alum on silk.

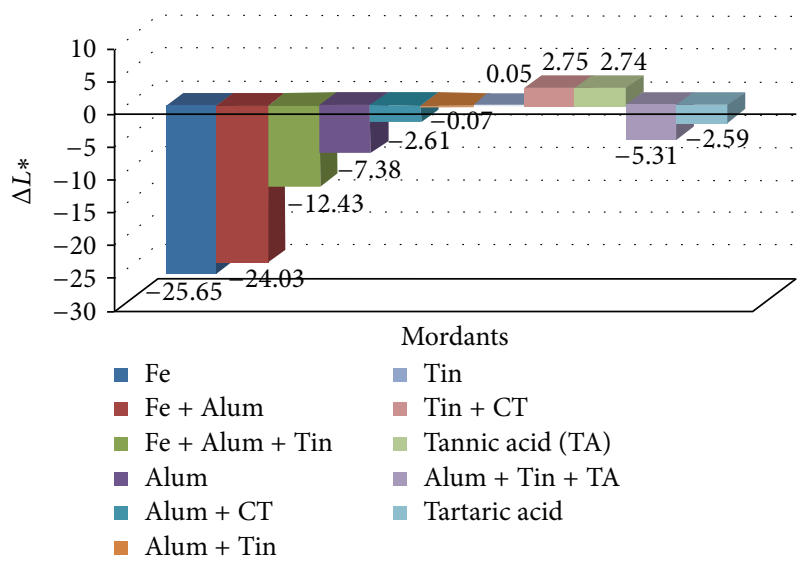

FIGURE 5: $\Delta L^{*}$ values of dyed silk.

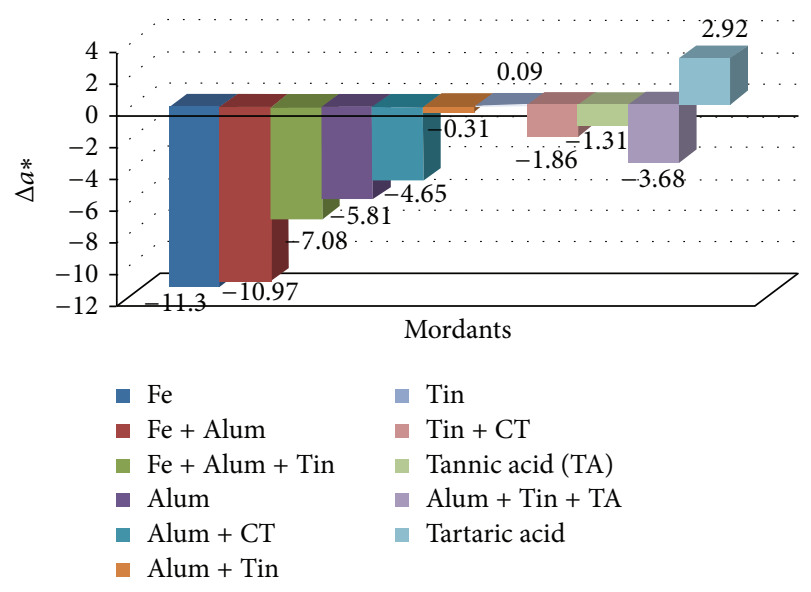

FigURE 6: $\Delta a^{*}$ values of dyed silk.

yellowness was increased in case of alum, alum-tin, and alumtin-tannic acid combinations which were $37.32 \%, 32.87 \%$, and $23 \%$, respectively, over the reference dyed sample.

The color saturation values $\left(C^{*}\right)$ were found least in ferrous sulphate mordanted samples (19.09) whereas the values were found maximum in case of alum-tin (37.065) and alum (36.25) mordanted samples. In addition, the hue angles lie within $56.84^{\circ}$ to $77.82^{\circ}$, so all of the dyed samples were closer to yellowish shade than the reddish.

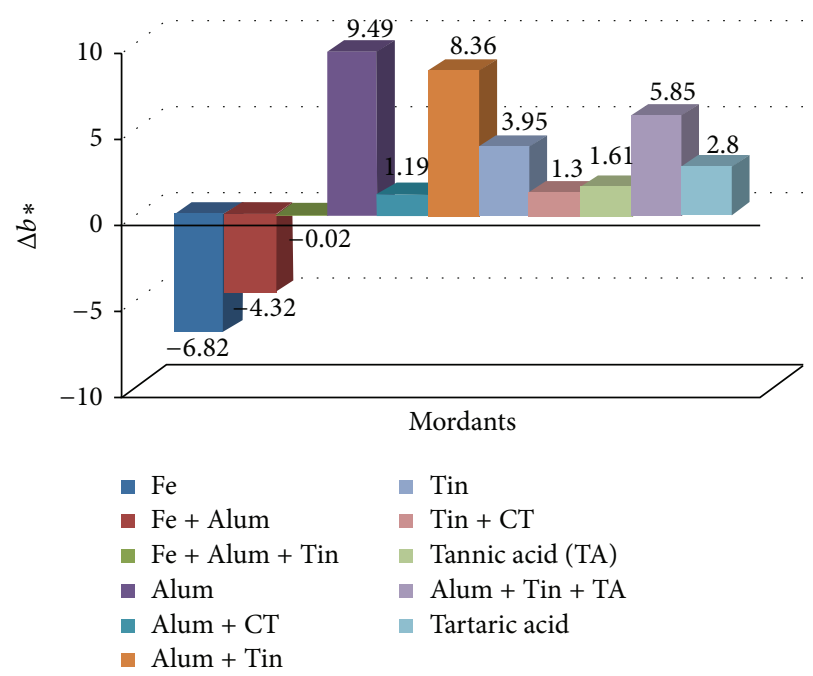

Figure 7: $\Delta b^{*}$ values of dyed silk.

3.2.3. Color Difference $\left(\triangle E_{C M C}\right)$. The most striking results were found in case of ferrous sulphate mordanted samples. Higher color difference was noticeable between reference and ferrous sulphate mordanted samples and the color difference reduced from ferrous sulphate to alum and then alum to tin in case of metallic mordants as shown in Table 2. Again, the $\Delta E_{\mathrm{CMC}}$ value between reference and nonmetallic mordanted fabric sample was found lower than that between reference and metallic mordanted fabric sample.

\subsection{Fastness Results}

3.3.1. Washing Fastness. The results of washing, light, and rubbing fastness of the dyed fabrics were shown in Table 3.

The unmordanted dyed silk showed rating 4 . Using mordants and combinations, the color change ratings were found within $3 / 4$ to 5 , where rating 5 (Excellent) was found using tin, tin-CT, tannic acid, and tartaric acid mordants. The ratings were found 4 in case of using alum, alum-CT, and alum-tintannic acid. So it can be said that overall ratings of color change were good. As wash fastness of dye is influenced by the rate of diffusion of dye molecules and state of dyes inside the fiber, it can be explained that they have a tendency to aggregate inside the fiber. Thus, their molecular size is 
TABLE 3: Washing, light, and dry cleaning fastness of dyed fabrics.

\begin{tabular}{|c|c|c|c|c|c|c|c|c|c|c|}
\hline \multirow{3}{*}{ Mordant type } & \multirow{3}{*}{$\mathrm{CC}^{*}$} & \multicolumn{6}{|c|}{ Washing fastness } & \multirow{3}{*}{$\begin{array}{c}\text { Light } \\
\text { fastness } \\
\text { (CC) }\end{array}$} & \multirow{2}{*}{\multicolumn{2}{|c|}{$\begin{array}{c}\text { Dry } \\
\text { cleaning }\end{array}$}} \\
\hline & & & & $\mathrm{CS}^{*}$ & & & & & & \\
\hline & & Di-acetate & Bleached cotton & Polyamide & Polyester & Acrylic & Wool & & $\mathrm{CC}$ & CS \\
\hline No mordant (Reference dyed) & 4 & 5 & 5 & 5 & 5 & 5 & 5 & 4 & $4 / 5$ & 5 \\
\hline $\mathrm{Fe}$ & $3 / 4$ & 5 & 5 & 5 & 5 & 5 & 4 & 6 & 5 & 5 \\
\hline $\mathrm{Fe}+$ Alum & 3 & 5 & 5 & 5 & 5 & 5 & 4 & 6 & 4 & 5 \\
\hline $\mathrm{Fe}+$ Alum + Tin & $3 / 4$ & 5 & 5 & 5 & 5 & 5 & 4 & 7 & $4 / 5$ & 5 \\
\hline Alum & 4 & 5 & 5 & 5 & 5 & 5 & 5 & 4 & 4 & 5 \\
\hline Alum + CT & 4 & 5 & 5 & 5 & 5 & 5 & 5 & 4 & $4 / 5$ & 5 \\
\hline Alum + Tin & 3 & 5 & 5 & 5 & 5 & 5 & 4 & 3 & 4.5 & 5 \\
\hline Tin & 5 & 5 & 5 & 5 & 5 & 5 & 5 & 3 & 5 & 5 \\
\hline Tin + CT & 5 & 5 & 5 & 5 & 5 & 5 & 5 & 3 & $4 / 5$ & 5 \\
\hline Tannic acid (TA) & 5 & 5 & 5 & 5 & 5 & 5 & 5 & 3 & $4 / 5$ & 5 \\
\hline Alum + Tin + TA & 4 & 5 & 5 & 5 & 5 & 5 & 5 & 4 & $4 / 5$ & 5 \\
\hline Tartaric acid & 5 & 5 & 5 & 5 & 5 & 5 & 5 & 3 & $4 / 5$ & 5 \\
\hline
\end{tabular}

$\mathrm{CC}^{*}$ : color change; $\mathrm{CS}^{*}$ : color staining.

increased which exhibits good wash fastness. In addition, in case of mordanted samples, complexing with mordant has the effect of insolubilizing the dye, making it color fast.

Moreover, this can be explained that the good fastness to washing for the sample dyed without mordant was due to the affinity of coloring component through $\mathrm{H}$-bonding and van der Waals forces.

On the other hand, the color staining ratings were found from 4 to 5 for all the dyed fabrics, except when ferrous sulphate and its combinations were used as mordants. There were very slight staining observed on the adjacent wool fiber of the multifiber fabrics in case of ferrous sulphate and its combination as well as alum-tin samples where ratings were found 4 and almost no staining on the other fibers of the multifiber fabric.

3.3.2. Light Fastness. As shown in Table 3, the unmordanted dyed fabric showed rating 4 and this was improved to 6 using ferrous sulphate mordant. The rating was further improved to 7 using ferrous sulphate-alum-tin combination. In other cases, in comparison to unmordanted sample, rating was either unchanged or decreased by 1 grade.

As ferrous sulphate has more affinity towards dye and fiber compared to tin or alum, it can be said that ferrous sulphate can bind with more dye molecules than tin or alum. The fabrics mordanted with ferrous sulphate, alum, or tin may have the same number of dye molecules destroyed during exposure to light. But as the fabrics mordanted with ferrous sulphate had deeper shades due to bonding with more number of dye molecules, it seemed to fade less compared to the fabric mordanted with tin or alum.

It has been clearly shown that ferrous sulphate mordanted samples dyed with the extracts showed excellent light fastness. This happened due to the formation of a complex with transition metal which protected the chromophore from photolytic degradation. The photons which were sorbed by the chromophoric group dissipated their energy by resonating within the six member ring formed, thus protecting the dye.

3.3.3. Dry Cleaning Fastness. The dry cleaning fastness ratings as shown in Table 3 for both color change and color staining to the perchloroethylene solution were found within 4 to 5 . Only in case of color change rating of alum and ferrous sulphate-alum, the rating was 4 and in all other cases it was within $4 / 5$ to 5 . In most cases, it can be stated that the pelargonidin dyes were almost completely resistant to perchloroethylene solution.

3.3.4. Rubbing Fastness. From the comparison carried out between the staining ratings of dry and wet rubbing fastness as shown in Figure 8, it was noticed that dry rubbing fastness was found slightly better than wet rubbing fastness.

All the staining ratings of dry rubbing fastness were ranged within 4 to 5 . Besides the overall better dry rubbing fastness, the wet rubbing fastness of the ferrous sulphatealum-tin and alum-tin-tannic acid combinations was 3 and in other cases it was ranged within $3 / 4$ and 5 .

3.3.5. Perspiration Fastness. The results of color fastness to perspiration test are shown in Table 4. In most of the cases, the color change ratings found for acid perspiration were higher than the corresponding ratings for alkaline perspiration. But the reverse trend was found in case of alum-CT and tin-CT mordanted samples. Equal ratings for color change of both acid and alkaline perspiration tests were achieved in case of ferrous sulphate-alum-tin, alum-tin-tannic acid, and tartaric acid mordanted samples.

Among the staining results, significant to moderate staining (rating 2/3) was noticeable only in three cases on wool fiber of the multifiber fabrics under acidic perspiration (i.e., ferrous sulphate, ferrous sulphate-alum-tin, and alum-tin 
Table 4: Perspiration fastness of dyed fabrics.

\begin{tabular}{|c|c|c|c|c|c|c|c|c|c|c|c|c|c|c|}
\hline \multirow{3}{*}{ Mordant type } & \multirow{2}{*}{\multicolumn{2}{|c|}{$\begin{array}{l}\text { Color } \\
\text { change }\end{array}$}} & \multicolumn{12}{|c|}{ Color staining to adjacent multifiber fabric } \\
\hline & & & \multicolumn{2}{|c|}{ Di-acetate } & \multicolumn{2}{|c|}{ Bleached cotton } & \multicolumn{2}{|c|}{ Polyamide } & \multicolumn{2}{|c|}{ Polyester } & \multicolumn{2}{|c|}{ Acrylic } & \multicolumn{2}{|c|}{ Wool } \\
\hline & $\mathrm{Ac}^{*}$ & $\mathrm{Ak}^{*}$ & Ac & $\mathrm{Ak}$ & Ac & $\mathrm{Ak}$ & Ac & $\mathrm{Ak}$ & Ac & $\mathrm{Ak}$ & Ac & $\mathrm{Ak}$ & Ac & $\mathrm{Ak}$ \\
\hline No mordant (Reference dyed) & $4 / 5$ & 4 & 3 & $3 / 4$ & 4 & 4 & 4 & $4 / 5$ & 3 & 4 & 3 & $3 / 4$ & 4 & 4 \\
\hline $\mathrm{Fe}$ & $3 / 4$ & 3 & $3 / 4$ & $4 / 5$ & $2 / 3$ & 4 & 3 & $4 / 5$ & 3 & 4 & 3 & 4 & $2 / 3$ & 4 \\
\hline $\mathrm{Fe}+$ Alum & 4 & $3 / 4$ & 4 & $4 / 5$ & 3 & 3 & $3 / 4$ & $3 / 4$ & $3 / 4$ & $3 / 4$ & $3 / 4$ & $3 / 4$ & $3 / 4$ & 3 \\
\hline $\mathrm{Fe}+$ Alum + Tin & $3 / 4$ & $3 / 4$ & 4 & $4 / 5$ & $2 / 3$ & $3 / 4$ & 3 & 4 & 3 & 4 & 3 & 4 & $2 / 3$ & $3 / 4$ \\
\hline Alum & 4 & $3 / 4$ & 4 & 4 & $4 / 5$ & $4 / 5$ & $4 / 5$ & $4 / 5$ & $4 / 5$ & $4 / 5$ & 4 & 4 & $4 / 5$ & $4 / 5$ \\
\hline Alum + CT & $3 / 4$ & $4 / 5$ & $4 / 5$ & 4 & $4 / 5$ & $4 / 5$ & $4 / 5$ & $4 / 5$ & $4 / 5$ & $4 / 5$ & 4 & 4 & $4 / 5$ & $4 / 5$ \\
\hline Alum + Tin & 4 & $3 / 4$ & $3 / 4$ & $4 / 5$ & 3 & 3 & 3 & $3 / 4$ & 3 & $3 / 4$ & 3 & $3 / 4$ & $2 / 3$ & 3 \\
\hline Tin & $3 / 4$ & 3 & 4 & $3 / 4$ & $4 / 5$ & 4 & $4 / 5$ & 4 & $4 / 5$ & $3 / 4$ & 4 & 3 & $4 / 5$ & $4 / 5$ \\
\hline Tin + CT & 4 & $4 / 5$ & $3 / 4$ & $3 / 4$ & $4 / 5$ & $4 / 5$ & $3 / 4$ & $4 / 5$ & $3 / 4$ & $4 / 5$ & $4 / 5$ & 3 & $4 / 5$ & 4 \\
\hline Tannic acid (TA) & $4 / 5$ & $3 / 4$ & $4 / 5$ & $2 / 3$ & $4 / 5$ & $3 / 4$ & $4 / 5$ & 4 & 4 & 3 & 4 & $2 / 3$ & $4 / 5$ & $3 / 4$ \\
\hline Alum + Tin + TA & $4 / 5$ & $4 / 5$ & 4 & $4 / 5$ & $4 / 5$ & 5 & $4 / 5$ & $4 / 5$ & $4 / 5$ & $4 / 5$ & 4 & $3 / 4$ & $4 / 5$ & $4 / 5$ \\
\hline Tartaric acid & 4 & 4 & $3 / 4$ & $3 / 4$ & 4 & 4 & 4 & $4 / 5$ & $3 / 4$ & 3 & 3 & 3 & $4 / 5$ & 4 \\
\hline
\end{tabular}

$\mathrm{Ac}^{*}$ : ratings when treated under acidic perspiration solution, while $\mathrm{Ak}^{*}$ : under alkaline perspiration solution.

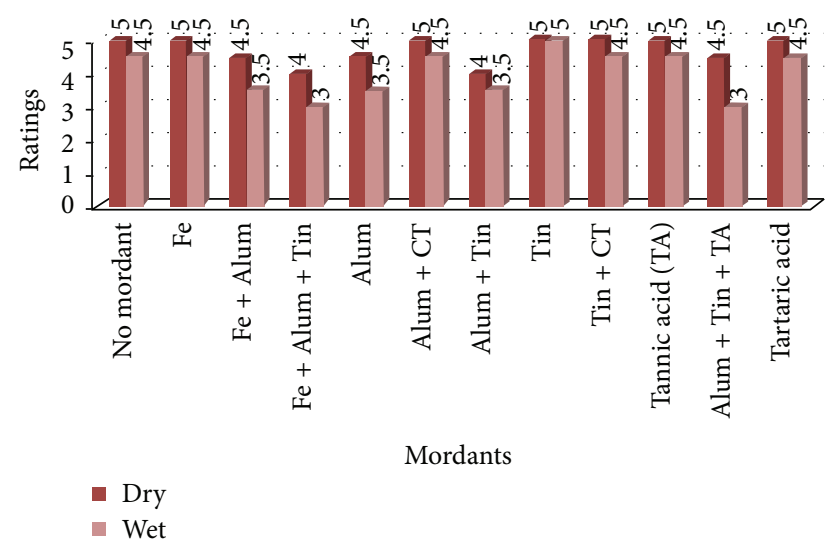

FIGURE 8: Rubbing fastness results of dyed fabrics.

mordanted samples), in one case on the acrylic fiber under alkaline condition (i.e., tannic acid mordanted sample), one case of on di-acetate fiber under alkali perspiration (tannic acid mordanted sample), and two cases on bleached cotton under acidic perspiration (ferrous sulphate and ferrousalum-tin mordanted sample). These are the cases that affected the ratings most. All other staining results were found to be satisfactory.

Test data of perspiration indicated that there were changes noticeable in the dyed samples after treating under the perspiration solutions, and this may be due to several factors, such as the ionization of some of the dyes during alkaline perspiration testing or some dyes may detach from the substrate from the dye-fiber bond (between the skin dye and the silk fiber) during acidic perspiration treatments.

\section{Conclusions}

This study demonstrated that onion outer skins can be used as a potential source of dyes for dyeing of silk fabric. This gave the chance to produce different fashion hues on silk fabric from the same dye extract of onion skins using metallic and nonmetallic mordants and their combinations. It was concluded that the color values with respect to $K / S$ and $L^{*}$, $a^{*}, b^{*}$ values were found to be influenced by the addition of mordants. Ferrous sulphate was found as the most influential mordant with respect to color values. Mordants improved $K / S$ values of the dyed fabrics except a few cases when compared to unmordanted dyed fabrics. Using ferrous sulphate, alum, tin, tannic acid, and tartaric acid as a single mordant on silk, the order of color yield found was ferrous sulphate $>$ tartaric acid $>$ tin $>$ tannic acid $>$ alum. Again, among the combinations ferrous sulphate-alum, ferrous sulphate-alumtin, alum-tin, and alum-tin-tannic acid, the order found was ferrous sulphate-alum $>$ ferrous sulphate-alum-tin $>$ alumtin $>$ alum-tin-tannic acid. Fastness properties were found satisfactory and improved in many cases. Light fastness rating was improved from 4 to 7 using ferrous sulphate-alumtin combination. Furthermore, there is a tremendous scope to use the extracted dyes on silk fabric without using any mordant. The plant dyes extracted from onion skins can be considered as a copartner with synthetic dyes for dyeing of silk fabric. The areas where synthetic dyes, fixatives, and other additives are imported and are, therefore, relatively expensive; the plant dyes especially from this type of waste materials can offer an attractive alternative.

\section{Conflict of Interests}

The author of the paper has declared that he has no conflict of interests.

\section{Acknowledgment}

The author would like to express his gratitude to Professor Dr. Md. Zulhash Uddin (Dean, Faculty of Textile Chemical Processing Engineering and Applied Science, Bangladesh 
University of Textiles) due to his technical cooperation in this work.

\section{References}

[1] E. Tsatsaroni, M. Liakopoulou-Kyriakides, and I. Eleftheriadis, "Comparative study of dyeing properties of two yellow natural pigments-effect of enzymes and proteins," Dyes and Pigments, vol. 37, no. 4, pp. 307-315, 1998.

[2] T. Bechtold, A. Turcanu, E. Ganglberger, and S. Geissler, "Natural dyes in modern textile dyehouses-how to combine experiences of two centuries to meet the demands of the future?" Journal of Cleaner Production, vol. 11, no. 5, pp. 499509, 2003.

[3] P. Saravanan and G. Chadramohan, "Dyeing of silk with ecofriendly natural dye obtained from Barks of Ficus religiosa L," Universal Journal of Environmental Research and Technology, vol. 1, no. 3, p. 268, 2011.

[4] L. G. Angelini, A. Bertoli, S. Rolandelli, and L. Pistelli, "Agronomic potential of Reseda luteola $\mathrm{L}$. as new crop for natural dyes in textiles production," Industrial Crops and Products, vol. 17, no. 3, pp. 199-207, 2003.

[5] Z. M. Win and M. M. Swe, "Purification of the natural dyestuff extracted from Mango bark for the application on protein fibers," World Academy of Science, Engineering and Technology, vol. 22, p. 536, 2008.

[6] S. Waheed and A. Alam, "Studies of some natural dyes," Journal of the Chemical Society of Pakistan, vol. 26, no. 3, pp. 255-263, 2004.

[7] S. Chandravanshi and S. K. Upadhyay, "Interaction of natural dye (Allium cepa) with ionic surfactants," Journal of Chemistry, vol. 2013, Article ID 685679, 6 pages, 2013.

[8] F. M. Tera, K. E. Elnagar, and S. M. Mohamed, "Dyeing and light fastness properties of onion scale dye on different fabric types for conservative applications," Journal of Textile and Apparel, Technology and Management, vol. 7, no. 3, pp. 1-6, 2012.

[9] A. Önal, "Extraction of dyestuff from onion (Allium cepa L.) and its application in the dyeing of wool, feathered-leather and cotton," Turkish Journal of Chemistry, vol. 20, no. 3, pp. 194-203, 1996.

[10] R. Mongkholrattanasit, J. Kryštůfek, J. Wiener, and M. Vikov, "Dyeing, fastness, and uv protection properties of silk and wool fabrics dyed with eucalyptus leaf extract by the exhaustion process," Fibres and Textiles in Eastern Europe, vol. 86, no. 3, pp. 94-99, 2011.

[11] H. Böhmer, Koekboya: Natural Dyes and Textiles: A Colour Journey from Turkey to India and Beyond, Remhöb, Ganderkesee, Germany, 2002.

[12] S. S. Kulkarni, U. M. Bodake, and G. R. Pathade, "Extraction of natural dye from chili (Capsicum Annum) for textile coloration," Universal Journal of Environmental Research and Technology, vol. 1, pp. 58-63, 2011.

[13] A. C. Dweck, "Natural ingredients for colouring and styling," International Journal of Cosmetic Science, vol. 24, no. 5, pp. 287302, 2002.

[14] D. Cardon, Natural Dyes: Sources, Tradition, Technology and Science, Archetype Publications, London, UK, 2007.

[15] G. Arroyo-Figueroa, G. M. L. Ruiz-Aguilar, G. CuevasRodriguez, and G. G. Sanchez, "Cotton fabric dyeing with cochineal extract: influence of mordant concentration," Coloration Technology, vol. 127, no. 1, pp. 39-46, 2011.
[16] B. Glover, "Are natural colorants good for your health? Are synthetic ones better?" Textile Chemist and Colorist, vol. 27, no. 4, pp. 17-20, 1995.

[17] T. Bechtold and R. Mussak, Eds., Handbook of Natural Colorants, John Wiley \& Sons, West Sussex, UK, 2009.

[18] Clariant Manual. Recommendations for Dyeing Silk, Sandoz Chemicals, Basel, Switzerland.

[19] R. Mcdonald, Ed., Color Physics for Industry, Society of Dyers and Colourists, Bradford, UK, 2nd edition, 1997.

[20] S. D. Bhattacharya and A. K. Shah, "Metal ion effect on dyeing of wool fabric with catechu," Coloration Technology, vol. 116, no. 1, pp. 10-12, 2000.

[21] M. Rekaby, A. A. Salem, and S. H. Nassar, "Eco-friendly printing of natural fabrics using natural dyes from alkanet and rhubarb," The Journal of the Textile Institute, vol. 100, no. 6, pp. 486-495, 2009.

[22] R. Mongkholrattanasit and N. Punrattanasin, "Properties of silk fabric dyed with Eucaliptus, Quercetin, Rutin and Tannin using padding techniques," in Proceedings of the RMUTP International Conference on Textiles \& Fashion, Bangkok, Thailand, July 2012.

[23] F. A. Cotton and G. Wilkinson, Advanced Inorganic Chemistry: A Comprehensive Text, John Wiley \& Sons, New York, NY, USA, 3rd edition, 1972. 

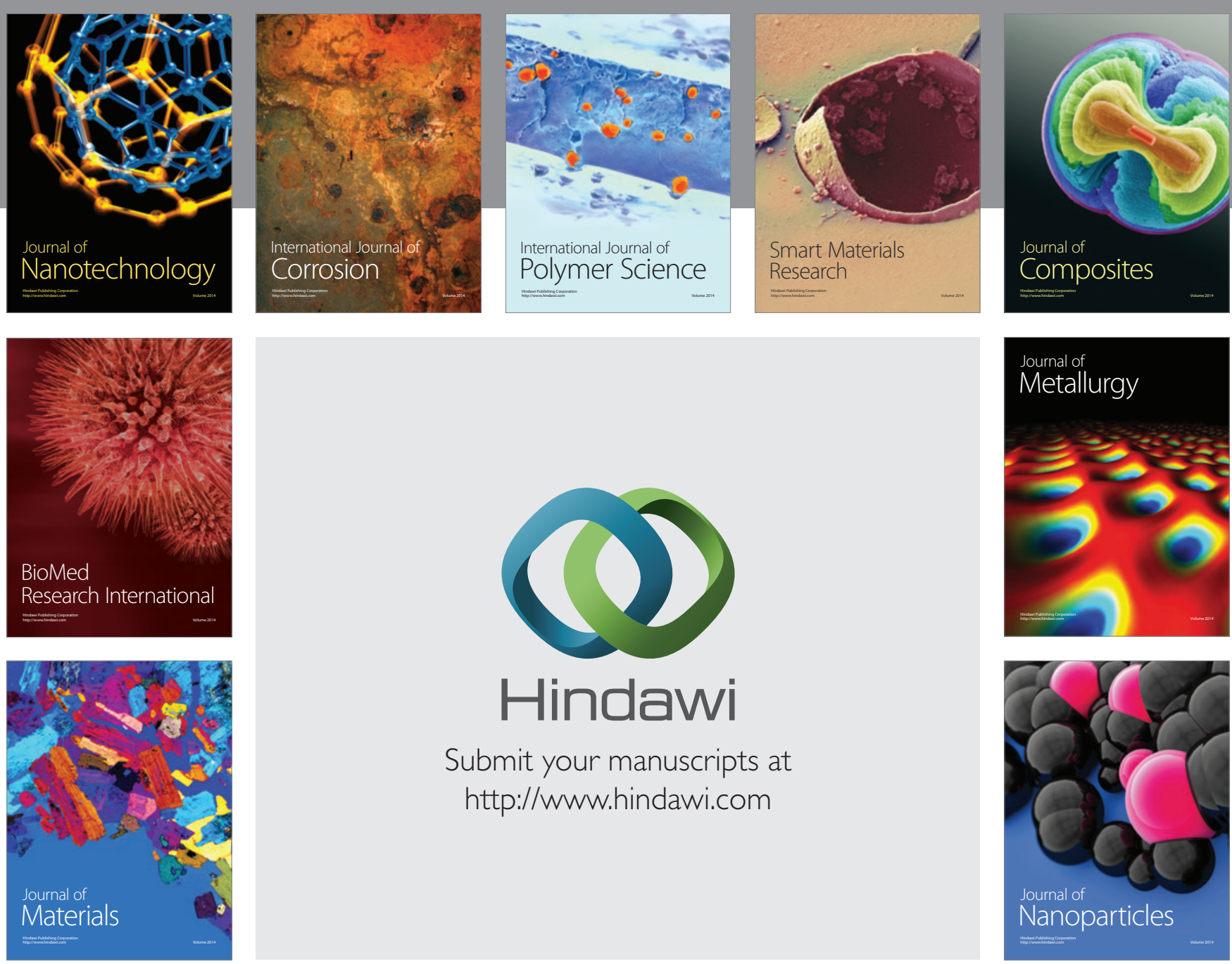

Submit your manuscripts at http://www.hindawi.com
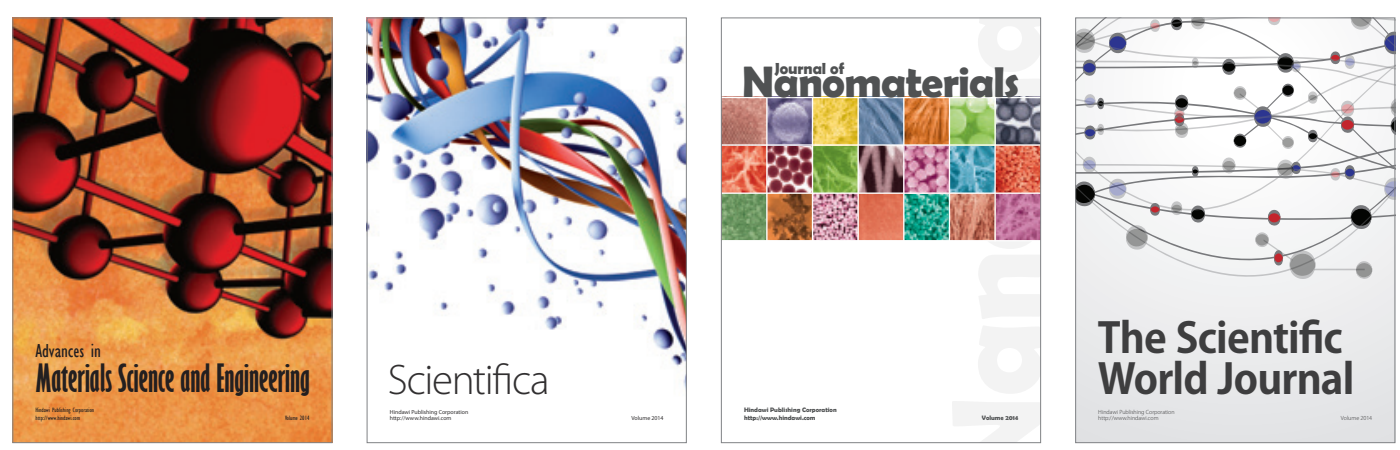

\section{The Scientific World Journal}
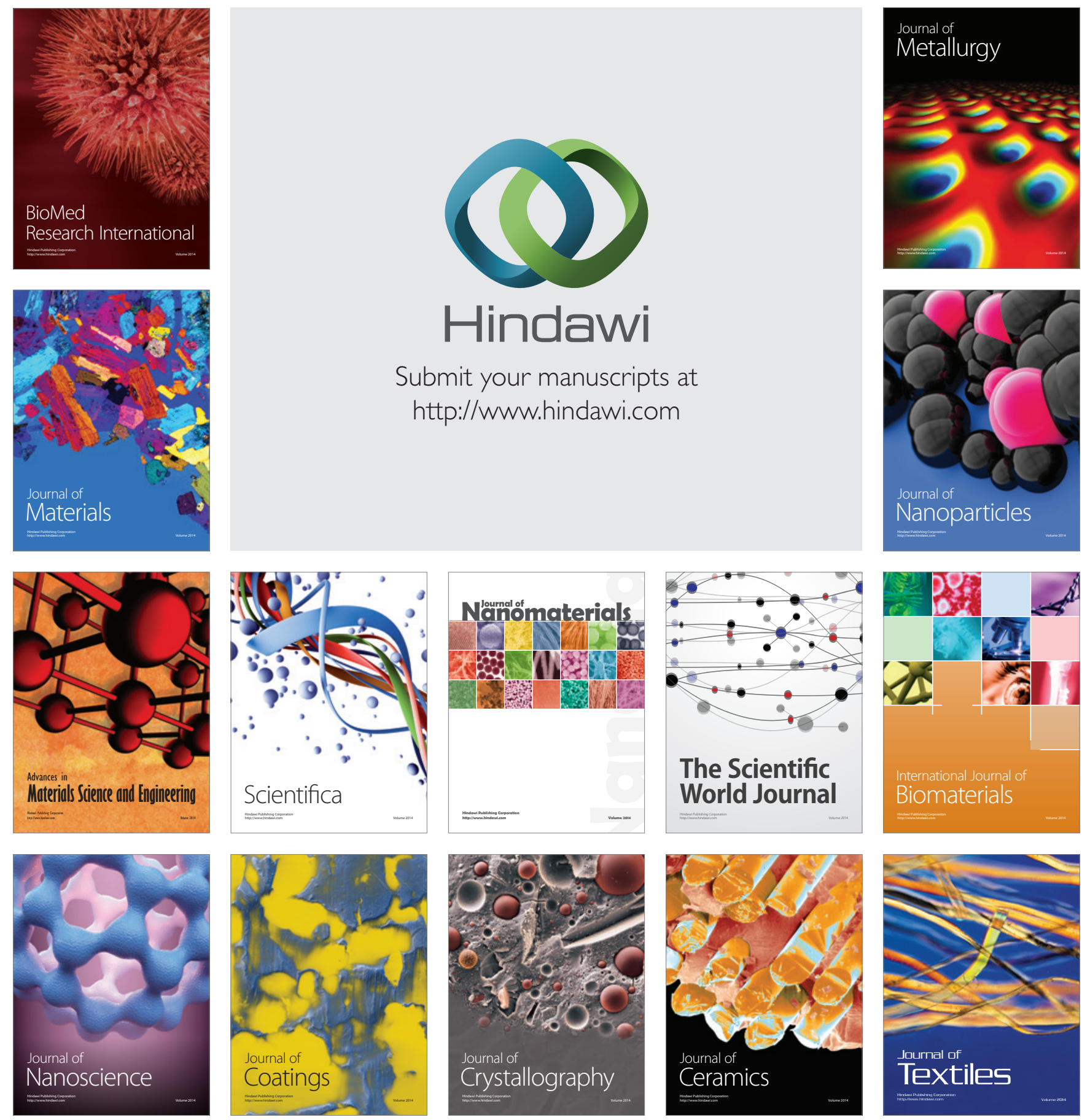